\section{Pengaruh Sponsorship pada Event Bingen Fest Terhadap Brand Awareness Authenticity Clas Mild}

Lontar: Jurnal Ilmu Komunikasi, 2021

Vol.9 (2), 2021 Copyright (C2021, Pelliyezer Karo Karo, et al. This is an open access article under the CC$B Y$-SA license DOI 10.30656/lontar.v9i2.3245

Article History

Submission: 22 April 2021

Revised: 06 November 2021 Accepted: 09 November 2021

\author{
Pelliyezer Karo Karo ${ }^{1 *}$, Annis Sabilla Firstyana ${ }^{2}$ \\ ${ }^{1}$ Politeknik Pariwisata Palembang \\ Email: pelliyezer@poltekpar-palembang.ac.id* \\ ${ }^{2}$ Politeknik Pariwisata Palembang \\ Email: firstyanaa@gmail.com \\ ${ }^{*}=$ Correspondent Author $)$
}

\begin{abstract}
Corporate investment in the form of sponsorship is often carried out to establish and maintain information stability in consumers, which leads to brand awareness of products and companies. The amount of the sponsorship budget is often not on target so that its effectiveness cannot be measured. In this regard, by taking the case of the Bingen Fest event in Palembang, the research was conducted aimed at identifying how far the influence of sponsorship by Clas Mild on the development of Brand Awareness Authenticity, so that it can be used as a basis for consideration of sponsorship financing in the future. The research sample consisted of 213 respondents who were visitors to the event and the research analysis used was simple linear regression. The test results show that 90.6 percent of the event segment is generation $Z$ with a visit repetition rate of 64.88 percent. Clas Mild sponsorship itself has a strong impact with a large influence of 49.1 percent on the development of Brand Awareness Authenticity.
\end{abstract}

Keywords: Sponsorship, Brand awareness, Authenticity, Bingen Fest

\begin{abstract}
ABSTRAK
Investasi perusahaan berbentuk sponsorship kerap dilakukan untuk menjalin dan menjaga stabilitas informasi di konsumen yang bermuara pada brand awareness dari produk maupun perusahaan. Besaran anggaran sponsorship seringkali tidak tepat sasaran sehingga tidak dapat diukur efektifitasnya. Berkaitan dengan hal tersebut, dengan mengambil kasus event Bingen Fest di Palembang penelitian dilakukan bertujuan mengidentifikasi seberapa jauh pengaruh sponsorship yang dilakukan Clas Mild terhadap pembangunan Brand Awareness Authenticity, sehingga dapat dipergunakan sebagai dasar pertimbangan pembiayaan sponsorship kedepannya. Sampel penelitian berjumlah 213 responden yang merupakan pengunjung event tersebut dan analisis penelitian yang digunakan adalah regresi linear sederhana. Hasil pengujian menunjukkan bahwa 90,6 persen segmen event adalah generasi $\mathrm{Z}$ dengan tingkat repetisi kunjungan sebesar 64,88 persen. Sponsorship Clas Mild sendiri berdampak kuat dengan besar pengaruh sebesar 49,1 persen terhadap pembangunan Brand Awareness Authenticity.
\end{abstract}

Kata Kunci: Sponsorship, Brand awareness, Authenticity, Bingen Fest 


\section{PENDAHULUAN}

Perkembangan bisnis mengalami perubahan dengan sangat cepat, pertumbuhan pasar yang melonjak seiring dengan persaingan yang ketat, tidak terkecuali bagi industri rokok. TCSC (Tobacco Control Support Center) Indonesia dalam publikasi Atlas Tembakau Indonesia 2020, juga dalam mencatat tren produksi rokok muai dari tahun 2012 selalu berada diatas angka lebih dari 320 miliar batang per tahun dengan tren ekspor impor tembakau berada di angka lebih dari 29 ribu ton eskpor di tahun 2017 (www.tcsc-indonesia.org). Bersamaan dengan kemajuan teknologi yang memudahkan antar pesaing mendapatkan informasi serta meningkatnya permintaan pasar oleh konsumen menuntut perusahaan untuk dapat bersaing dengan berbagai strategi di lingkungan bisnis. Dalam usaha untuk dapat mencapai target perusahaan dan bertahan di pasar diperlukan dukungan pemasaran produk yang baik sebagai alat komunikasi langsung dengan konsumen sehingga dapat mempengaruhi minat konsumen terhadap produk perusahaan tersebut dan bertahan di pasar (Keller, 2013). Pemasaran dan persaingan pasar ini dialami oleh semua jenis bisnis dan perusahaan termasuk perusahaan rokok merupakan salah satu perusahaan yang juga menjalani persaingan pasar dengan perusahaan rokok lainya. Untuk dapat bertahan di pasar dan bersaing dengan produk rokok emiten maka perusahaan rokok juga perlu melakukan strategi pemasaran yang baik agar dapat mengkomunikasikan produknya kepada calon konsumen.

Komunikasi dan pemasaran yang perlu dilakukan oleh perusahaan rokok ini sekarang dikenal sebagai komunikasi pemasaran (marketing communication). Seiring dengan perkembangan pasar, yang menyebabkan berkembangnya komunikasi kepada pasar atau komunikasi pemasaran berkembang menjadi lebih kompleks lagi yaitu komunikasi pemasaran terpadu (integrated marketing communication, IMC) (Keller, 2013). Beberapa tools yang terdapat dalam IMC serta untuk melaksanakan IMC yaitu iklan, memperkenalkan penjualan, promosi penjualan, pemasaran langsung, hubungan masyarakat, word of mouth, dan dukungan sponsor (event marketing and sponsorship) (Belch Georg E. \& Michael A. Belch Michael A., 2018). Namun, dari keenam tools terpadu untuk melaksanakan IMC tersebut perusahaan rokok tidak dapat memilih dengan bebas untuk menggunakannya agar dapat mencapai target pencapaian pasar yang sesuai dari perusahaan. Hal ini dikarenakan rokok merupakan satu dari sekian produk yang memiliki keterbatasan dalam pemasaran promosi dengan larangan tidak semua bentuk alat promosi dapat digunakan oleh rokok sebab elemen dalam pengawasan FCTC mencakup antara lain pelarangan iklan dan melakukan promosi rokok, pembahasan perdagangan internasional, desain dan pencantuman label standar kesehatan berupa gambar pada bungkus rokok.

Terdapat berbagai bentuk aturan dari peraturan internasional dan juga kebijakan pemerintah. World Health Organization (WHO) membuat kebijakan yang mengatur produksi, promosi, dan penggunaan tembakau dalam aturan yang disebut Kerangka Kerja Konvensi Pengendalian Tembakau atau Framework Convention on Tobacco Control (FCTC) yang diberlakukan di tingkat Internasional dengan kesepakatan 191 negara dalam sidang WHO ke-56 pada tahun 2003 untuk mengatasi dampak buruk tembakau seluruh negara yang termasuk di dalamnya adalah Indonesia. FCTC mengatur seluruh aspek bisnis yang mengandung tembakau yaitu salah satunya adalah larangan mengenai penggunaan segala jenis iklan dan promosi produk tembakau oleh perusahaan. Hal inilah yang membuat ruang batas gerak promosi penjualan produk rokok menjadi sempit. Termasuk pemberian sponsor produk-produk rokok baik secara langsung dan tidak langsung.

Banyak negara segera menerapkan FCTC tersebut secara keseluruhan, namun Indonesia belum sepenuhnya melegalkan FCTC. Salah satu poin batasan rokok yang belum dilegalkan oleh Indonesia adalah pelarangan memberi finansial kepada suatu kelompok maupun kegiatan atau yang dikenal dengan istilah sponsorship (www.tobaccocontrollaws.org). Sponsorship merupakan jalan promosi produk tembakau yang diminati sangat tinggi oleh perusahaan rokok dalam komunikasi merek pada tahap awal pengembangan awareness (Dharmawan Salim, 2013). Redmandarin menjelaskan hasil survey tentang tujuan perusahaan untuk melakukan investasi sponsorship yang diambil dari European Sponsors'. Peningkatan brand awareness merupakan 
grafik tertinggi dalam tujuan utama perusahaan dengan angka yang mencapai 69 persen, lalu pada grafik tingkat kedua yaitu tujuan memberikan tanggung jawab sosial dan komunitas dengan angka 22 persen (Masterman, 2012). Event sponsorship merupakan strategi penting untuk memenangkan kompetisi pada target pasar dengan peluang tinggi terhadap pengembalian dari investasi perusahaan (O’Halloran, 2014).

Berbagai bentuk sponsorship dapat dilakukan oleh perusahaan rokok, namun sponsorship yang dilakukan pada event tertentu menjadi peminatan tertinggi oleh perusahaan untuk dilakukan. Event yang menjadi pilihan paling populer adalah event seni dan olahraga dikarenakan kedua event tersebut merupakan event universal dan memiliki peminat yang tinggi (Cianfrone, 2018). Salah satu perusahaan rokok yang juga sedang marak melakukan sponsorship ialah PT Nojorono Tobacco yang merupakan satu dari lima merek rokok emiten di Indonesia. Agar dapat bertahan di pasaran PT Nojorono Tobacco perlu mengikuti perkembangan pasar dan juga melakukan komunikasi pemasaran kepada konsumennya dengan cara promosi. Salah satu produk rokok ternama dari PT Nojorono Tobacco yang paling sering muncul ke pasaran dalam hal sponsorship adalah rokok Clas Mild.

Tindakan langsung ( $a c t$ ) atau interaksi dengan konsumen menjadi variabel dengan pengaruh terbesar dalam proses pemasaran (Karo Karo, 2019). Interaksi Clas Mild dalam mengenalkan diri kepada segmen pasar dituju menjadi produk rokok yang ingin menciptakan brand image sebagai rokok yang terbuka dan menerima terhadap keberagaman yang diekspresikan, Clas Mild ingin menjadi partner bagi setiap orang untuk mempertahankan keunikan dirinya yang tertuang pada slogan barunya sejak 2016 lalu hingga saat ini yaitu "Simply Authentic". Clas Mild hadir di setiap kota-kota besar dengan mengadakan event musik atau bergabung menjadi sponsor dalam konser musik dengan sebutan Authenticity. Authenticity menjadi nama panggung Clas Mild pada setiap event musik yang diadakan Clas Mild dan event musik yang disponsori Clas Mild. Dalam menjalankan fungsi pemasaran, maka citra sebuah produk menjadi sangat penting untuk memastikan konsumen mengingat dan melakukan pembelian ulang. Dalam penelitiannya, Pratiwi memperoleh hasil berkaitan dengan produk rokok bahwa brand awareness menjadi salah satu faktor penting dan signifikan terhadap purchase intention (Pratiwi, 2017). Sedangkan dalam kaitannya dengan IMC dan pengalaman konsumen, penelitian Vitadiani berhasil menunjukkan bahwa sponsorship merupakan faktor yang memiliki pengaruh positif terhadap brand awareness (Vitadiani \& Mudiantono, 2016). Dalam membangun citra Clas Mild yang diekspresikan dengan unsur keterbukaan dan keberagaman maka event musik yang sejalan dengan raihan Clas Mild tersebut adalah event musik bertemakan indie. Jalinan hubungan sponsorhip dengan musik bertemakan indie juga bertujuan untuk mengangkat musik indie di pasaran yang lebih global di Indonesia. Salah satu kota besar yang dibanjiri event musik Clas Mild adalah Palembang, mulai dari event musik yang Clas Mild adakan sendiri hingga mensponsori banyak event musik di Palembang.

Tabel 1. Event Authenticity Tahun 2019

\begin{tabular}{cll}
\hline No. & \multicolumn{1}{c}{ Nama Event } & \multicolumn{1}{c}{ Tempat dan Tanggal Pelaksanaan } \\
\hline 1. & Authentic Moment with Fourtwnty & Bingen Cafe, 08 Februari 2019 \\
2. & Authentic Moment with Fiersa Besari & Unsilent, 09 Maret 2019 \\
3. & Authentic Moment with Iksan Skuter & Guns Cafe \& Resto, 28 April 2019 \\
4. & Authentic Moment with Sisitipsi & Guns Cafe \& Resto, 04 Agustus 2019 \\
5. & Authentic Moment with Efek Rumah Kaca & Area 51, 31 Agustus 2019 \\
6. & Authentic Moment with Float & Guns Cafe \& Resto, 15 September 2019 \\
7. & Authenticity Bingen Fest & PSCC, 22 September 2019 \\
8. & Authenticity Fest & PSCC, 29 September 2019 \\
\hline
\end{tabular}

Sumber: Authenticity Palembang, 2020

Clas Mild merupakan perusahaan rokok yang sangat aktif dalam hal sponsorship event musik di Palembang, dengan konsep yang selalu konsisten dengan tujuannya yaitu mengangkat musik indie nasional maupun lokal. Salah satu event musik yang konsisten disponsori oleh Clas Mild sejak tahun 2016 hingga 2019 adalah event Bingen Fest. Event Bingen Fest yang dianggap selalu 
dapat memunculkan talenta indie baru dan tidak membosankan merupakan acara live music yang diselenggarakan oleh Bingen Live sejak tahun 2016 dan direncanakan menjadi event yang hadir setiap tahun. Bingen Fest merupakan acara konser musik indie yang diadakan di cafe Bingen yang berada di pinggir kota Palembang. Pada penyelenggaraan tiga tahun pertama Bingen Live sukses menarik pengunjung untuk datang ke event Bingen Fest, dengan rata rata pengunjung yang datang selalu melampaui target pengunjung yang Bingen Live targetkan, dengan data pengunjung Bingen Fest berikut:

Tabel 2. Data Pengunjung Bingen Fest

\begin{tabular}{ccccc}
\hline No. & Penyelenggaraan Event & Venue & $\begin{array}{c}\text { Target Pengunjung } \\
\text { (orang/hari) }\end{array}$ & $\begin{array}{c}\text { Total Pengunjung } \\
\text { (orang/hari) }\end{array}$ \\
\hline 1. & 8-10 Desember 2016 & Bingen Cafe & 900 & \pm 750 \\
2. & 4-5 November 2017 & Bingen Cafe & 900 & \pm 950 \\
3. 20-21 Oktober 2018 & Bingen Cafe & 900 & $950-1000$ \\
4. & 22 September 2019 & PSCC & 2000 & 1411 \\
\hline
\end{tabular}

Sumber: Bingen Fest, 2020

Penelitian terkait respon terhadap program sponsorship dengan mengambil kasus pada penyelenggaraan sports event, diketahui bahwa eksposure konsumen pada sponsorship dipengaruhi oleh attitudes toward the event, attitudes toward the sponsor dan perception of congruence between sponsor and event. Dalam penelitian tersebut, faktor sponsorship diteliti melalui variabel tunggal sponsor-event fit dan faktor sponsor diteliti melalui tiga variabel yaitu attitude to sponsor, sincerity of sponsor dan ubiquity of sponsor (Speed \& Thompson, 2000). Berhubungan dengan brand awareness, Keller dalam bukunya Strategic Brand Management, mengindikasikan pengukuran secara kuantitatif dari brand awareness dapat dilakukan pada dua indikator yaitu brand recognition dan brand recall yang sebelumnya dikenal dengan brand linkage (Keller, 2013). Menggunakan dua dasar teori oleh Speed dan Keller, penelitian ini juga berlandaskan penelitian pada event Java Jazz Festival tahun 2012 yang berfokus pada hubungan sponsorship terhadap brand awareness menunjukkan penguatan pada hasil penelitian yaitu pengaruh signifikan antara faktor sponsorship dan faktor sponsor terhadap brand awareness (Chintya \& Februarini, 2012). Sehingga berdasarkan hal tersebut, defenisi operasional variabel dalam penelitian ini seperti terlampir pada tabel 3.

Tabel 3. Definisi Operasional Variabel

\begin{tabular}{|c|c|c|}
\hline Indikator & Definisi & Pernyataan \\
\hline \multicolumn{3}{|c|}{ Variabel Sponsorship } \\
\hline \multicolumn{2}{|c|}{ Tingkat kesesuaian antara } & 1 Kesesuaia \\
\hline \multicolumn{2}{|c|}{ Sponsor - Event sponsor dan event yang disponsori } & 2. Kemiripan Citra antara event dan \\
\hline \multicolumn{2}{|c|}{ Fit dengan mengukur hubungan logis, } & 3. Tema event dan sponsor memiliki tujuan yang sama \\
\hline \multicolumn{2}{|c|}{$\begin{array}{ll}\text { Attitude } & \text { to } \begin{array}{l}\text { Tingkat persepsi baik dan buruk } \\
\text { oleh pengunjung terhadap } \\
\text { Sponsor }\end{array}\end{array}$} & 1. Sikap pengunjung terhadap perusahaan sponsor \\
\hline $\begin{array}{l}\text { Sincerity } \\
\text { sponsor }\end{array}$ & $\begin{array}{l}\text { Persepsi mengenai ketulusan } \\
\text { sponsor untuk memberikan } \\
\text { sponsorship kepada event. }\end{array}$ & $\begin{array}{l}\text { 1. Tanggapan bahwa event terlihat terbantu oleh adanya } \\
\text { sponsor melalui jalur publikasi } \\
\text { 2. Konsistensi komitmen sponsor yang mendukung event } \\
\text { 3. Dukungan sponsor secara mutlak pada keseluruhan acara. }\end{array}$ \\
\hline \multicolumn{2}{|c|}{$\begin{array}{ll}\text { Ubiquity } & \text { of } \\
\text { sponsor } & \text { sehingga mensponsori jenis event } \\
& \text { dalam memberikan sponsor } \\
& \text { kepada event. }\end{array}$} & $\begin{array}{l}\text { 1. Sponsor fokus dalam memberikan sponsor kepada } \\
\text { 2. event tertentu } \\
\text { 3. Sponsor terlihat selektif dalam memilih event untuk } \\
\text { diberikan sponsor } \\
\text { 4. Perusahaan terlihat aktif untuk mensponsori event dengan } \\
\text { jenis tertentu }\end{array}$ \\
\hline \multicolumn{3}{|c|}{ Variabel Brand awareness } \\
\hline \multirow{2}{*}{$\begin{array}{l}\text { Brand } \\
\text { Recognition }\end{array}$} & $\begin{array}{lr}\text { Kemampuan konsumen untuk } \\
\text { mengidentifikasi }\end{array}$ & $\begin{array}{l}\text { 1. Kemudahan mengenali merek melalui nama yang ada pada } \\
\text { event }\end{array}$ \\
\hline & $\begin{array}{l}\text { terhadap suatu merek dengan } \\
\text { stimulus-stimulus } \\
\text { sebagai bantuan. }\end{array}$ & $\begin{array}{l}\text { 2. Kemudahan mengenali merek melalui logo } \\
\text { 3. Kemudahan mengenali merek melalui slogan } \\
\text { 4. Kemudahan mengenali merek melalui kemasan event }\end{array}$ \\
\hline
\end{tabular}




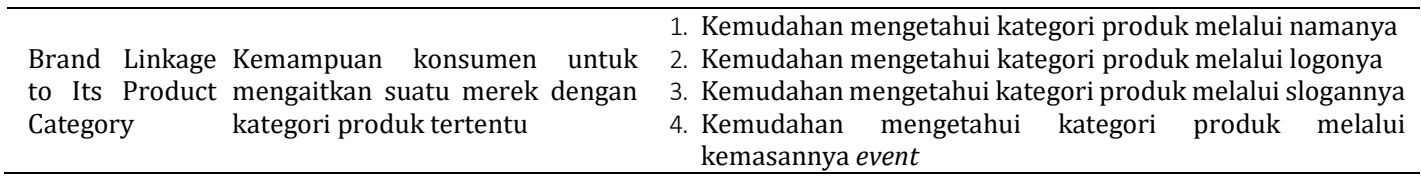

Sumber: Hasil penelitian, 2020

Besarnya biaya sponsorship yang selalu dianggarkan pada setiap penyelenggaraan event, tidak seiring dengan ketepatan sasaran dari capaian brand awareness yang sedang dibangun. Capaian hanya dinilai berdasarkan target pengunjung dan total kunjungan, sehingga tidak dapat diketahui dengan jelas apakah sponsorhsip yang dibangun selama ini berperan pada peningkatan informasi citra. Penelitian studi kasus pada Toyota Vietnam, menunjukkan bahwa melalui sponsorship dengan mediasi brand awareness mampu meningkatkan minat beli produk (Khuong \& Kim Chau, 2017). Sejalan dengan hal tersebut, hasil penelitian berkaitan dengan sponsorship pada sebuah merk smartphone menunjukkan bahwa sponsorship memiliki pengaruh positif signifikan terhadap brand sebuah produk (Larasari et al., 2018). Penelitian lain berkaitan dengan tanggapan sponsorship sebagai sebuah investasi menunjukkan bahwa sponsorship dalam sebuah event menjadi komunikasi pemasaran yang efektif dalam membangun brand awareness (Mpolokeng Sephapo, 2017). Dengan begitu, dalam penelitian ini dilakukan analisis untuk mengetahui bagaimana investasi yang dilakukan Clas Mild pada pangsa pasar Bingen Fest yang dituju untuk meraih brand awareness melalui pengukuran pengaruh sponsorship terhadap brand awareness Authenticity pada event Bingen Fest 2019, sehingga diharapkan Clas Mild akan mampu lebih efektif dalam menerapkan program sponsorship kedepannya.

\section{METODE PENELITIAN}

Penelitian ini merupakan penelitian kuantitatif dengan metode survei eksplanatori menggunakan analisis regresi linear sederhana. Objek penelitian adalah program sponsorship yang dilakukan oleh Clas Mild kepada Bingen Fest 2019. Subjek penelitian adalah seluruh pengunjung saat event Bingen Fest sejumlah 1411 pengunjung. Berdasarkan beberapa keterbatasan pada database penyelenggara, salah satunya pada identitas pengunjung, maka data real pengunjung yang dapat dijadikan dasar pengumpulan data primer berjumlah 354 orang sebagai populasi penelitian. Berdasarkan data tersebut, diperoleh parameter proporsi populasi senilai 0,251. Menggunakan pendekatan Krejcie Morgan dengan tingkat akurasi 5\% dan nilai chi square 3,84 maka diperoleh sampel berjumlah 240 responden.

Penelitian menggunakan metode purposive sampling berdasarkan dua syarat sebagai dasar karakteristik responden dengan ketentuan:

1. Umur

Kategori umur responden penelitian minimal 18 tahun, dikarenakan usia tersebut merupakan target konsumen dari perusahaan pemberi sponsor yaitu Clas Mild sebagai perusahaan rokok yang taat pada peraturan perundangan berlaku.

2. Ingatan atas event

Keterbatasan pada ruang dan waktu penelitian dari event yang sudah berlangsung sebelumnya, maka sample diharapkan merupakan responden yang masih mengingat event Bingen Fest sehingga diperoleh data yang lebih valid.

Kuesioner dibangun dengan tipe pertanyaan tertutup menggunakan skala likert bersifat favorable. Analisis statistik deskriptif penelitian dipergunakan untuk mendeskripsikan data sampel untuk mempermudah pembacaan data. Dua analisis kelompok data dalam uraian statistik deskriptif, mencakup karakteristik responden serta tanggapan rata- rata dan modus jawaban yang diberikan oleh responden dari setiap butir pertanyaan yang peneliti berikan. Dalam menganalisis karakteristik responden dilakukan frequency analysis sedangkan pada analisis tanggapan rata- rata dan modus dari jawaban responden dilakukan pendekatan mean dan mode per-indikator pernyataan. Pada analisis statistik inferensial dilakukan beberapa uji agar hasil analisis menjadi valid dan reliabel melalui uji instrumen, uji asumsi klasik dan uji regresi. 
Konversi data ordinal dari kuesioner menjadi data interval menggunakan method of successive interval sebelum melakukan uji instrumen, uji asumsi klasik dan uji regresi.

\section{ANALISIS DATA}

\section{Uji Instrumen}

Uji instrumen penelitian ini dilakukan pada 30 orang di luar sample. Pengujian dilakukan dalam dua tahap yaitu uji validitas dan uji reliabilitas, pengukuran validitas menggunakan pendekatan koefisien korelasi sedangkan pengukuran reliabilitas dengan pendekatan Cronbach's Alpha.

Tabel 4. Hasil Uji Validitas dan Uji Reabilitas

\begin{tabular}{cccc}
\hline \multicolumn{1}{c}{ Indikator } & Pernyataan & $\begin{array}{c}\text { Corrected } \\
\text { Correlation }\end{array}$ & $\begin{array}{c}\text { Cronbach's } \\
\text { Alpha }\end{array}$ \\
\hline \multirow{3}{*}{ Sponsor - Event Fit } & $\mathrm{Q} 1$ & .641 & .858 \\
& $\mathrm{Q} 2$ & .641 & .877 \\
Attitude to Sponsor & $\mathrm{Q} 3$ & .817 & .841 \\
& $\mathrm{Q} 1$ & .766 & .846 \\
Sincerity of sponsor & $\mathrm{Q} 1$ & .686 & .854 \\
& $\mathrm{Q} 2$ & .712 & .852 \\
& $\mathrm{Q} 3$ & .719 & .851 \\
Ubiquity of sponsor & $\mathrm{Q} 1$ & .589 & .866 \\
& $\mathrm{Q} 2$ & .752 & .848 \\
Q3 & .668 & .855 \\
Brand Recognition & $\mathrm{Q} 1$ & .739 & .859 \\
& $\mathrm{Q} 2$ & .533 & .875 \\
Q3 & .703 & .863 \\
Brand Linkage to & $\mathrm{Q} 4$ & .841 & .839 \\
Its Product Category & $\mathrm{Q} 1$ & .758 & .851 \\
& $\mathrm{Q} 2$ & .730 & .855 \\
Q3 & .662 & .863 \\
Sumber: Hasil pent & $\mathrm{Q} 4$ & .852 & .838 \\
\hline
\end{tabular}

Sumber: Hasil penelitian, 2020 (SPSS 24, diolah)

Berdasarkan tabel 4, nilai corrected correlation setiap butir pertanyaan lebih besar dari nilai korelasi minimum sebesar 0.361 , begitu juga dengan identifikasi reabilitas berdasarkan nilai cronbach alpha setiap butir pertanyaan lebih besar dari nilai minimum sebesar 0.700 , dengan begitu, instrumen yang dibangun telah memenuhi persyaratan valid dan reliabel untuk dipergunakan sebagai instrument penelitian.

\section{Uji Asumsi Klasik}

Analisis regresi dalam penelitian ini berbasis ordinary least square (OLS) sehingga sebagai uji persyaratan statistik berupa uji asumsi klasik, mencakup uji normalitas, uji heteroskedastisitas dan uji linearitas. Pada uji normalitas digunakan pendekatan histogram dan probability plot.
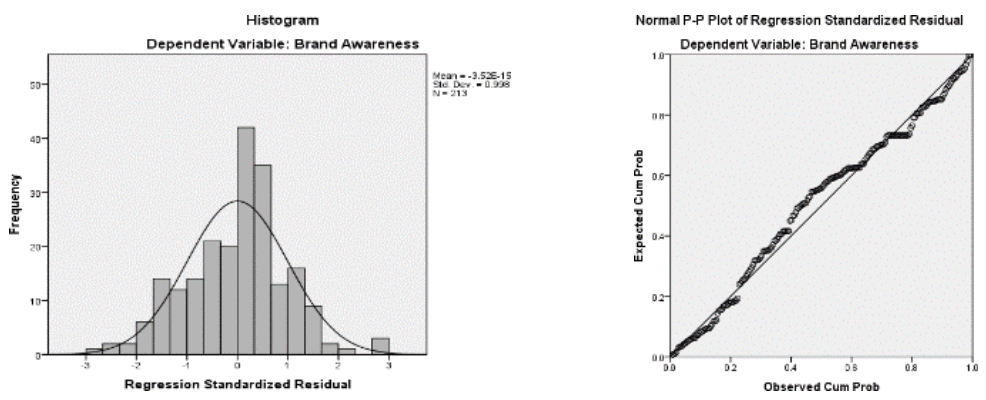

Gambar 1. Uji Histogram dan Probability Plot

Sumber : Hasil penelitian, 2020 (SPSS 24)

Grafik histogram menunjukan bahwa data residu yang dihasilkan terdistribusi secara normal, tidak condong ke kanan maupun ke kiri sehingga berbentuk seperti lonceng yang 
memperlihatkan data yang stabil dari awal hingga ke tengah dan juga akhir yang memperlihatkan tidak terdapat data yang jauh dari rerata total data responden tersebut. Berdasarkan grafik p-plot dapat disimpulkan bahwa data yang dihasilkan merupakan data terdistribusi normal, terlihat melalui titik bulatan yang menggambarkan data tersebar menyebar disekitar alur diagonal dan atau mengikuti garis diagonal tersebut.

Uji heteroskedastisitas digunakan untuk mengetahui adanya ketidaksamaan variasi residual dari suatu pengamatan model regresi, pada penelitian ini digunakan uji Glejser dan uji Rank Spearman.

Tabel 5. Uji Glejser

\begin{tabular}{|c|c|c|c|c|c|c|}
\hline \multicolumn{6}{|c|}{ Coefficients $^{\mathrm{a}}$} & \\
\hline & & \multicolumn{2}{|c|}{$\begin{array}{l}\text { Unstandardized } \\
\text { Coefficients }\end{array}$} & \multirow{2}{*}{$\begin{array}{c}\begin{array}{c}\text { Standardized } \\
\text { Coefficients }\end{array} \\
\text { Beta }\end{array}$} & \multirow{2}{*}{$\mathrm{t}$} & \multirow{2}{*}{ Sig. } \\
\hline & & B & $\begin{array}{l}\text { Std. } \\
\text { Error }\end{array}$ & & & \\
\hline \multirow[t]{2}{*}{$\overline{1}$} & (Constant) & $-1.355 \mathrm{E}-14$ & 1.898 & & .000 & 1.000 \\
\hline & Sponsorship & .000 & .043 & .000 & .000 & 1.000 \\
\hline
\end{tabular}

Sumber: Hasil penelitian, 2020 (SPSS 24)

Tabel 6. Uji Rank Spearman

\begin{tabular}{|c|c|c|c|c|}
\hline & & & Sponsorship & $\begin{array}{c}\text { Unstandardized } \\
\text { Residual }\end{array}$ \\
\hline \multirow{6}{*}{$\begin{array}{l}\text { Spearman's } \\
\text { rho }\end{array}$} & \multirow[t]{3}{*}{ Sponsorship } & $\begin{array}{l}\text { Correlation } \\
\text { Coefficient }\end{array}$ & 1.000 & .059 \\
\hline & & Sig. (2-tailed) & . & .389 \\
\hline & & $\mathrm{N}$ & 213 & 213 \\
\hline & \multirow{3}{*}{$\begin{array}{l}\text { Unstandardized } \\
\text { Residual }\end{array}$} & $\begin{array}{l}\text { Correlation } \\
\text { Coefficient }\end{array}$ & .059 & 1.000 \\
\hline & & Sig. (2-tailed) & .389 & \\
\hline & & $\mathrm{N}$ & 213 & 213 \\
\hline
\end{tabular}

Sumber: Hasil penelitian, 2020 (SPSS 24)

Hasil pengujian melalui pendekatan uji glejser dan uji rank spearmen menunjukkan bahwa nilai signifikansi variabel lebih besar dari $\alpha$ senilai 0,05 dapat ditarik kesimpulan bahwa model regresi dalam penelitian ini tidak terjadi heteroskedastiisatas.

Uji linieritas dilakukan untuk mengidentifikasi model regresi yang dipergunakan dikatakan linear atau nonlinear, dengan mendeteksi hubungan antar variabel menggunakan pendekatan test for linearity. Metode yang dipergunakan untuk mendeteksi hubungan linieritas antara variabel sponsorship dengan variabel brand awareness adalah metode scatterplot.

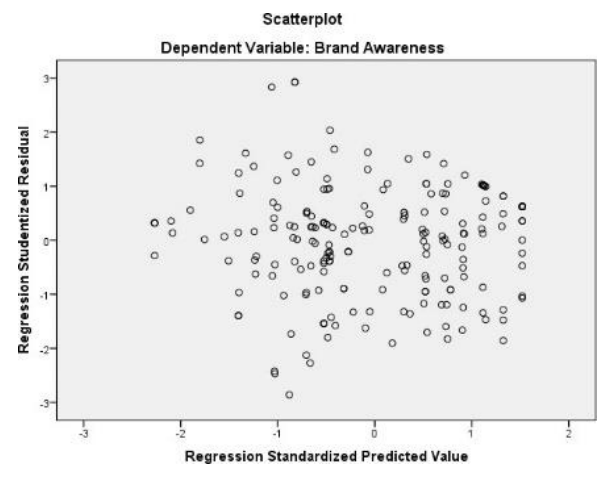

Gambar 2. Uji Scatterplot

Sumber: Hasil penelitian, 2020 (SPSS 24) 
Berdasarkan hasil uji scatterplot diketahui bahwa terlihat melalui titik bulatan menggambarkan penyebaran data melalui titik-titik tersebut, memenuhi bentuk tidak terkumpul pada satu tempat atau tidak menghasilkan pola tertentu, sehingga dapat ditarik kesimpulan bahwa data yang dihasilkan merupakan data linear dan memenuhi kaidah linearitas.

\section{Uji Korelasi}

Pengujian korelasi dimaksudkan untuk mengidentifikasi keeratan hubungan antara variabel sponsorship dengan variabel brand awareness, dalam penelitian ini kaitannya untuk menguji apakah terdapat hubungan antara pemberian sponsorship oleh Clas Mild dengan pembangunan brand awareness Authenticity.

Tabel 7. Uji Koefisien Korelasi

Correlations

\begin{tabular}{llrr}
\hline & & \\
\hline Sponsorship & Pearson Correlation & Sponsorship & Brand Awareness \\
& Sig. (2-tailed) & 1 & $.700^{* *}$ \\
& $\mathrm{~N}$ & 213 & .000 \\
Brand Awareness & Pearson Correlation & $.700^{* *}$ & 213 \\
& Sig. (2-tailed) & .000 & 1 \\
& $\mathrm{~N}$ & 213 & 213 \\
\hline **. Correlation is significant at the 0.01 level (2-tailed)
\end{tabular}

**. Correlation is significant at the 0.01 level (2-tailed).

Sumber: Hasil penelitian, 2020 (SPSS 24)

Tabel 7 menunjukkan bahwa nilai koefisien korelasi pearson antara variabel sponsorship dengan variabel brand awareness sebesar positif 0,7 mengindikasikan bahwa kedua variabel memiliki hubungan yang kuat dan searah dimana peningkatan metode sponsorship Clas Mild akan juga meningkatkan brand awareness Autenticity itu sendiri. Nilai sig. pada uji korelasi sebesar menunjukkan bahwa hubungan dari kedua variabel dimaksud juga terdeteksi memiliki korelasi yang signifikan.

\section{Uji Regresi Linear}

Analisis regresi linear sederhana digunakan untuk menganalisa hubungan pengaruh variabel independen yaitu sponsorship terhadap variabel dependen brand awareness, melalui persama regresi linear sederhana.

dimana:

$$
\mathrm{Y}=\mathrm{a}+\mathrm{bX}+\mathrm{e}
$$

$$
\begin{aligned}
& \mathrm{Y}=\text { Brand awareness } \\
& \mathrm{X}=\text { Sponsorship } \\
& \mathrm{a}=\text { konstanta } \\
& \mathrm{b}=\text { koefisen regresi } \\
& \mathrm{e}=\text { epsilon }
\end{aligned}
$$

Pengujian ini dilakukan untuk mengidentifikasi hubungan atau pengaruh antara variabel sponsorship Clas Mild dengan brand awareness Authenticity, bermuara pada perolehan perhitungan besaran peningkatan nilai brand awareness ketika dilakukan peningkatan sponsorship pada setiap satu poin. Berdasarkan Tabel 10. dapat diketahui nilai konstanta sebesar 3,891 dan nilai koefisien regresi sebesar 0,614, sehingga persamaan regresi linear yang terbentuk menjadi:

$$
Y=3,891+0,614 X
$$

Interpretasi dari persamaan regresi tersebut, antara lain:

1. Nilai konstanta sebesar 3,891 menunjukkan nilai tetap bagi variabel brand awareness apabila variabel sponsorship sama dengan nol, dengan kata lain, tanpa adanya sponsorship Clas Mild, 
brand awareness Authenticity telah memiliki nilai sebesar 3,891 bagi para konsumen.

2.Nilai koefisien regresi sebesar positif 0,614 dari variabel sponsorship menunjukkan setiap peningkatan satu satuan tingkat pada implementasi sponsorship Clas Mild akan memberikan dampak peningkatan sebesar 0,614 satuan tingkat bagi brand awareness Authenticity.

3. Nilai positif dari koefisien regresi menunjukkan bahwa implementasi sponsorship Clas Mild memberikan pengaruh positif bagi brand awareness Authenticity.

Pada penelitian ini, model regresi dianalisis pada nilai 95 persen confidence of interval dan nilai alpha 5 persen dimana tahapan pengujian berikutnya mencakup uji signifikansi (uji F), uji parsial (uji t) dan koefisien determinasi ( $\mathrm{R}^{2}$ ).

\section{HASIL DAN PEMBAHASAN}

\section{Analisis Karakteristik Responden}

Penyebaran instrumen penelitian berupa kuesioner kepada sejumlah responden yang telah memenuhi kriteria purposive sampling dengan total populasi sebesar 354 orang. Dengan beberapa keterbatasan dalam proses penelitian, diperoleh partisipasi pengisian instrumen diperoleh sebesar 213 responden. Adapun karakteristik responden dianalisis berdasarkan identifikasi terhadap jenis kelamin, usia, domisili, pekerjaan, pendidikan terakhir, tingkat pengeluaran.

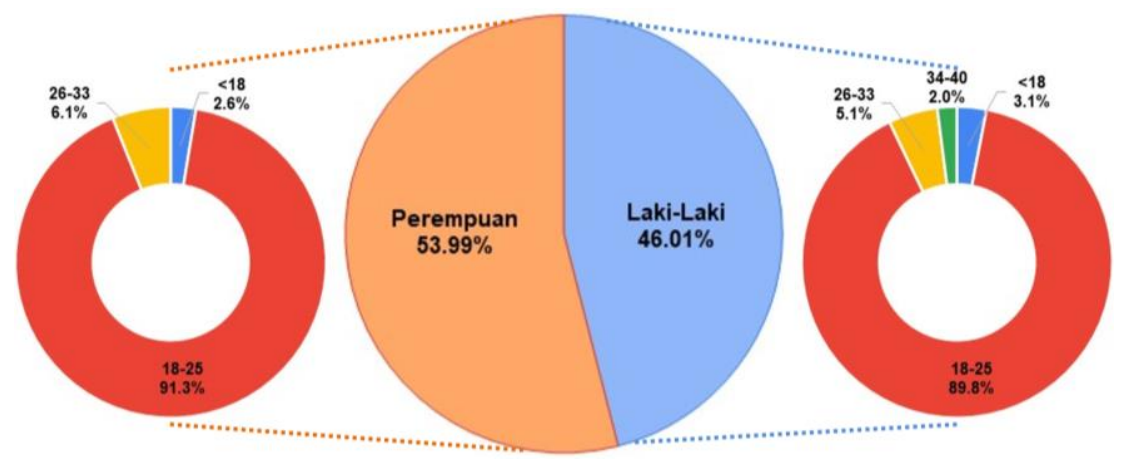

\section{Gambar 3. Karakteristik responden berdasarkan jenis kelamin dibagi atas usia} Sumber: Hasil penelitian, 2020

Berdasarkan Gambar 3. mengindikasikan bahwa event Bingen Fest dikunjungi oleh lebih banyak pengunjung perempuan sebesar delapan persen dibandingkan dengan pengunjung lakilaki. Baik pengunjung perempuan maupun laki-laki, masing-masing didominasi oleh lebih dari 89 persen dengan usia 18 hingga 25 tahun. Secara eksplisit, hal tersebut menunjukkan brand image Authenticity didominasi oleh generasi z baik pada gender laki-laki maupun perempuan.

Gambar 4. menunjukkan bahwa pengunjung event Bingen Fest didominasi berasal dari Palembang pada angka 82,16 persen, sedangkan sisanya berasal dari luar Palembang. Jika kedua domisili tersebut diturunkan berdasarkan jenis pekerjaan, diperoleh nilai yang hampir sama yaitu pada interval 72 hingga 74 persen pengunjung berstatus sebagai mahasiswa. Hal ini dapat menguatkan data sebelumnya pada Gambar 3. bahwa pengunjung didominasi oleh mahasiswa dengan rentang usia 18 hingga 25 tahun. 


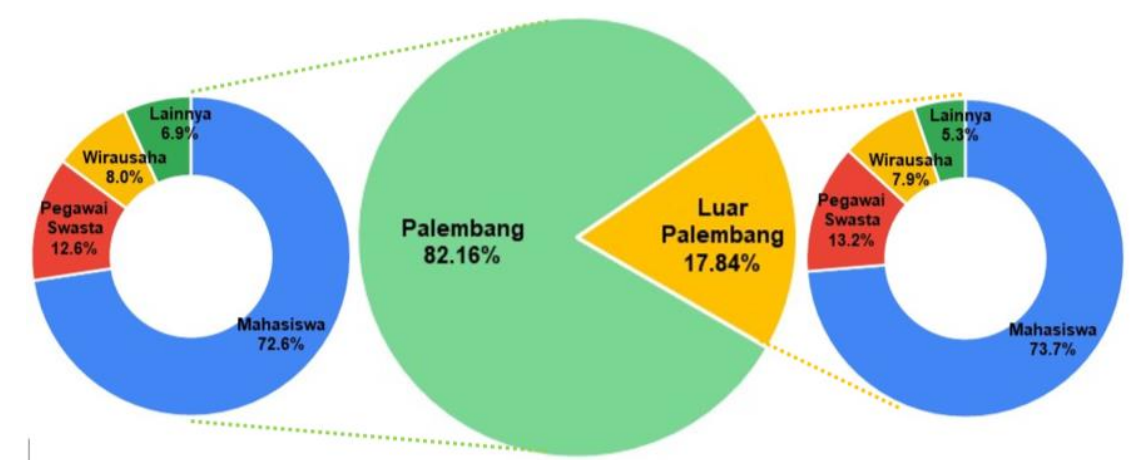

Gambar 4. Karakteristik responden berdasarkan domisili dibagi atas pekerjaan Sumber: Hasil penelitian, 2020
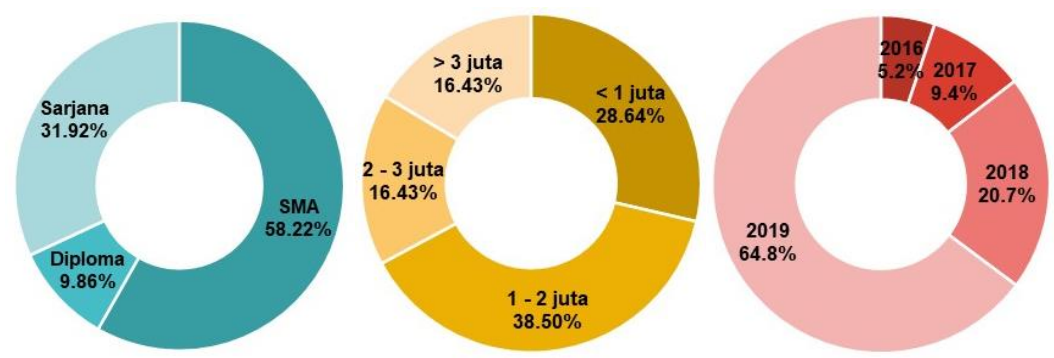

\section{Gambar 5. Karakteristik responden berdasarkan Tingkat Pendidikan, Tingkat Pengeluaran, dan Tingkat Repetisi Kunjungan}

Sumber: Hasil penelitian, 2020

Pengamatan pada Gambar 5. terlihat bahwa pengunjung event Bingen Fest hampir 60 persen dengan pendidikan terakhir SMA kemudian disusul sebesar hamper 32 persen berpendidikan terakhir sarjana. Jika dikombinasikan dengan data sebelumnya pada Gambar 4., dapat diketahui bahwa pengunjung didominasi oleh mahasiswa aktif program diploma atau sarjana berkisar 72 persen dengan pendidikan terakhir terendah adalah SMA. Berdasarkan tingkat pengeluaran, diketahui bahwa mendekati 55 persen pengunjung mengeluarkan rata-rata biaya sebesar 1 hingga 3 juta rupiah setiap bulannya, hal ini dapat menjadi pertimbangan kedepannya dalam menentukan strategi pelaksanaan event secara umum maupun dalam menentukan harga jual produk Clas Mild secara khusus. Ditinjau dari data repetisi kunjungan, dideteksi terdapat 20,7 persen merupakan pengunjung yang sama sejak tahun 2018, sedangkan 64,8 persen merupakan pengunjung baru pada event Bingen Fest.

\section{Analisis Tanggapan Responden}

Analisis dilakukan berdasarkan nilai rata-rata dan garis kontinum terhadap tanggapan responden dari setiap indikator dalam variabel sponsorship dan variabel brand awareness.

Tabel 8. Tanggapan Responden

\begin{tabular}{cccc}
\hline Indikator & Pernyataan & Mean & Kategori \\
\hline \multirow{2}{*}{ Sponsor-Event } & Q1 & 4.29 & Sangat Setuju \\
Fit & Q2 & 3.85 & Setuju \\
& Q3 & 4.31 & Sangat Setuju \\
Attitude to & Rerata & 4.15 & Setuju \\
Sponsor & Q1 & 4.28 & Sangat Setuju \\
Sincerity of & Q1 & 4.28 & Sangat Setuju \\
Sponsor & Q2 & 4.28 & Sangat Setuju \\
& Q3 & 4.28 & Sangat Setuju \\
& Rerata & 4.28 & Sangat Setuju \\
& Q1 & 4.27 & Sangat Setuju
\end{tabular}




\begin{tabular}{cccc} 
Ubiquity of & Q2 & 4.12 & Setuju \\
Sponsor & Q3 & 4.33 & Sangat Setuju \\
& Rerata & 4.24 & Sangat Setuju \\
Brand & Q1 & 4.33 & Sangat Setuju \\
Recognition & Q2 & 4.49 & Sangat Setuju \\
& Q3 & 4.08 & Setuju \\
Q4and Linkage to & Rerata & 3.83 & Setuju \\
Its Product & Q1 & 3.18 & Setuju \\
Category & Q3 & 3.85 & Setuju \\
& Q4 & 3.61 & Setuju \\
& Rerata & 3.86 & Setuju \\
\hline
\end{tabular}

Sumber: Hasil penelitian, 2020

Berdasarkan Tabel 8, diketahui bagaimana tanggapan respoden terhadap sponsorship dan brand awareness, terangkum dalam beberapa poin berikut:

1. Indikator sponsor-event fit.

Secara keseluruhan pernyataan pada indikator sponsor-event fit mendapatkan tanggapan positif dengan nilai rata-rata indikator dari perolehan responden berada pada angka 4,15 dengan kategori setuju. Akan tetapi, diketahui pada Q2, pernyataan mengenai kesamaan tujuan sponsor dengan event disponsori memperoleh nilai rata-rata 3,85 bermakna bahwa walaupun masih tergolong kelas interval setuju namun terdapat tanggapan ragu hingga negatif sebesar 30,9 persen mengenai kesamaan tujuan dari Authenticity dan Bingen Fest.

2. Indikator attitude to sponsor

Dalam sudut pandang pengunjung, hampir keseluruhan responden setuju bahwa Clas Mild - Authenticity merupakan perusahaan yang memiliki sikap baik sebagai sponsor, terlihat bahwa nilai rata-rata indikator mencapai angka 4.28 dengan kategori sangat setuju. Indikator kedua ini memiliki nilai tertinggi dibandingkan dengan indikator lainnya, sesuai dengan hasil penelitian Hutabarat (2014) mengindikasikan bahwa sikap sebagai sponsor memiliki faktor pengaruh positif dalam kesesuaian pemilihan sponsorship event.

3. Indikator sincerity of sponsor

Pada indikator ini, terlihat bahwa responden secara dominan setuju dengan ketulusan sponsor Clas Mild - Authenticity pada event Bingen Fest. Ditunjukkan dengan perolehan nilai mean dari setiap butir pernyataan dengan nilai $>4,21$ dengan rata-rata indikator pada angka 4.28 merupakan kategori sangat setuju, sehingga dapat diinterpretasikan bahwa responden sangat setuju dengan ketiga pernyataan dalam indikator sincerity of sponsor.

4. Indikator ubiquity of sponsor

Hasil tanggapan responden terhadap indikator ubiquity of sponsor dalam variabel sponsorship terlihat bahwa secara dominan responden memberi tanggapan positif terhadap keaktifan sponsor dalam program sponsorship, dibuktikan melalui nilai mean indikator sebesar 4,24 yang merupakan kategori sangat setuju. Akan tetapi, terdapat satu butir pernyataan dengan nilai mean berbeda yang masuk kategori setuju dengan nilai mean butir sebesar 4,12 yaitu pandangan responden bahwa Clas Mild - Authenticity terkait selektifitas sponsor dalam memilih event.

5. Indikator brand recognition

Tanggapan positif responden pada indikator brand recognition tercermin pada nilai ratarata indikator pada angka 4,18 yang termasuk dalam kategori setuju. Jika ditelaah lebih lanjut, terdapat dua butir pernyataan yang memperoleh tanggapan lebih dari 25 persen responden pada status ragu hingga negatif. Butir pertama berkenaan dengan kemampuan responden mengenali merk melalui stimulus kemasan produk Clas Mild pada angka 37,1 persen, dan butir kedua terfokus stimulus melalui slogan pada angkka 26,3 persen. Tetapi, pada indikator ini juga terdapat nilai tanggapan tertinggi dari seluruh butir, yaitu pada bantuan melalui stimulus logo dengan nilai mean sebesar 4,49 dimana 88.2 persen responden memberikan tanggapan positif. 
6. Indikator brand linkage to its product category

Berdasarkan hasil tanggapan responden, diketahui indikator brand linkage to its product category mendapatkan nilai rata-rata indikator di angka 3,76 dengan kelas kategori setuju. Bila diamati setiap butir pernyataan didalamnya, terlihat jelas bahwa seluruh butir berada pada kategori yang sama yaitu setuju dengan nilai yang juga tidak berbeda jauh, menunjukkan seluruh responden memiliki penilaian sejenis dalam kemampuan mengaitkan merk dengan produk Clas Mild. Hal ini dikuatkan dengan data bahwa hanya 56 hingga 66 persen responden yang memberikan tanggapan positif.

\section{Uji Signifikansi}

Hasil dari uji signifikansi (uji sig.) digunakan untuk menguji rumusan hipotesis melalui nilai sig. pada perolehan hasil pengujian. Rumusan hipotesis dimaksud yaitu:

Ho = Tidak ada pengaruh sponsorship Clas Mild terhadap brand awareness Authenticity $\mathrm{Ha}=$ Ada pengaruh sponsorship Clas Mild terhadap brand awareness Authenticity

Tabel 9. Hasil Uji ANOVA

\begin{tabular}{rlrrrrr}
\multicolumn{7}{c}{ ANOVA $^{\mathrm{a}}$} \\
\hline & \multicolumn{1}{c}{ Model } & Sum of Squares & Df & Mean Square & \multicolumn{1}{c}{ F } & Sig. \\
\hline \multirow{2}{*}{1} & Regression & 3211.372 & 1 & 3211.372 & 203.254 & $.000^{\mathrm{b}}$ \\
& Residual & 3333.754 & 211 & 15.800 & & \\
& Total & 6545.127 & 212 & & & \\
\hline
\end{tabular}

a. Dependent Variable: Brand awareness

b. Predictors: (Constant), Sponsorship

Sumber: Hasil penelitian, 2020 (SPSS 24)

Berdasarkan Tabel 10 dapat diketahui nilai signifikansi hasil pengujian, nilai tesebut dibandingkan nilai probabilitas $\alpha$ sebesar 0,05. Nilai Sig. sebesar $0.000<\alpha$ mengandung arti bahwa terdapat pengaruh sponsorship Clas Mild terhadap brand awareness Authenticity, dengan begitu Ho ditolak dan Ha diterima.

\section{Uji Parsial (uji t)}

Uji parsial selain digunakan untuk menguji pengaruh variabel independent terhadap variabel dependent secara parsial, juga dapat digunakan untuk memperkuat pengujian hipotesis, dengan membandingkan antara nilai t hitung dengan nilai t tabel $(\alpha, \mathrm{df})$.

Tabel 10. Tabel koefisien

\begin{tabular}{|c|c|c|c|c|c|c|}
\hline & \multicolumn{6}{|c|}{ Coefficients ${ }^{\mathrm{a}}$} \\
\hline & \multirow[t]{2}{*}{ Model } & \multicolumn{2}{|c|}{$\begin{array}{l}\text { Unstandardized } \\
\text { Coefficients }\end{array}$} & \multirow{2}{*}{$\begin{array}{c}\begin{array}{c}\text { Standardized } \\
\text { Coefficients }\end{array} \\
\text { Beta }\end{array}$} & \multirow[t]{2}{*}{$\mathrm{t}$} & \multirow[t]{2}{*}{ Sig. } \\
\hline & & $\mathrm{B}$ & Std. Error & & & \\
\hline \multirow[t]{2}{*}{1} & (Constant) & 3.891 & 1.898 & & 2.050 & .042 \\
\hline & Sponsorship & .614 & .043 & .700 & 14.257 & .000 \\
\hline
\end{tabular}

Hasil perbandingan menunjukkan bahwa nilai t hitung sebesar $14,257>t$ tabel $(0,05 ; 211)$ sebesar 1,971 mengandung arti bahwa secara parsial sponsorship Clas Mild juga memiliki pengaruh terhadap brand awareness Authenticity, dengan begitu hal ini memperkuat hasil pengujian hipotesis dimana Ho ditolak dan Ha diterima. Keeratan hubungan ini dapat menjadikan bahwa sponsorship menjadi salah satu faktor pengendali penting dalam mencapai penerapan brand awareness Authencity. 


\section{Koefisien Determinasi}

Pengujian koefisen determinasi dimaksudkan untuk mengetahui besaran pengaruh variabel independent sponsorship Clas Mild terhadap variabel dependent brand awareness Authenticity.

Tabel 11. Uji Koefisien Determinasi

\begin{tabular}{|c|c|c|c|c|}
\hline \multicolumn{5}{|c|}{ Model Summary ${ }^{b}$} \\
\hline Model & $\mathrm{R}$ & R Square & Adjusted R Square & $\begin{array}{l}\text { Std. Error of the } \\
\text { Estimate }\end{array}$ \\
\hline 1 & $.700^{\mathrm{a}}$ & .491 & .488 & 3.975 \\
\hline
\end{tabular}

Tabel 11 menunjukkan nilai koefisien $\mathrm{R}$ sebesar 0,700 bermakna bahwa pengaruh sponsorship Clas Mild terhadap brand awareness authencity berada pada klasifikasi berdampak kuat. Sedangkan nilai koefisien $\mathrm{R}$ square sebesar 0,491 mengindikasikan bahwa besaran pengaruh sponsorship Clas Mild terhadap brand awareness authencity berada di angka 49,1 persen, dengan kata lain bahwa dalam penelitian ini terdapat 50,9 persen lainnya bahwa brand awareness authencity dipengaruhi oleh variabel lainnya diluar implementasi sponsorship Clas Mild.

Hasil pengujian ini secara langsung menunjukkan kontribusi pola sponsorship Clas Mild yang diterapkan melalui event Bingen Fest hanya berpengaruh mendekati lima puluh persen terhadap pembentukan brand awareness dari Authenticity pada segmen pasar penikmat musik indie. Tentunya hasil ini menunjukkan pola sponsorship yang dijalankan ditinjau dari identifikasi empat indikator belum terlaksanan dengan efektif sehingga hal ini dapat dijadikan dasar evaluasi bagi dua hal utama yaitu konten sponsorship yang dibangun dan kesesuaian penetapan besaran anggaran sponsorship bagi perancangan event berikutnya.

\section{KESIMPULAN}

Mengacu pada tujuan dari penelitian yaitu mengetahui pengaruh sponsorship Clas Mild terhadap brand awareness Authenticity pada event Bingen Fest, maka berdasarkan analisis hasil penelitian diperoleh simpulan bahwa:

1.Segmen pasar utama event ini didominasi lebih dari 90 persen generasi z dimana 72 persen berstatus mahasiswa, sehingga membangun brand awareness dapat dilakukan melalui harga, daya tarik konten event atau intensitas promosi.

2.Nilai 84 persen tanggapan positif terhadap pelaksanaan sponsorship Clas Mild dengan angka 70 persen tanggapan positif terhadap brand awareness menunjukkan pengunjung belum terbiasa mengenali merk Authenticity, hal ini diperkuat dengan hasil bahwa walaupun sponsorship memiliki pengaruh positif terhadap pembangunan brand Class Mild tetapi nilainya hanya berkisar 49 persen. Hal dapat menunjukkan dua kemungkinan yaitu apakah pola sponsorship belum terlaksana efektif atau apakah ada faktor lain yang mempengaruhi benak pengunjung terhadap produk.

3.Terdapat dua hal yang dapat dilakukan pada pengembangan penelitian selanjutnya agar hasil diperoleh lebih komprehensif yaitu pengembangan pengujian data dan pengumpulan informasi saat event berlangsung.

\section{DAFTAR PUSTAKA}

Belch Georg E., \& Michael A. Belch Michael A. (2018). Advertising and Promotion An Integrated Marketing Communications Perspective, Sixth Edition. Sereal Untuk, 51(1).

Chintya \& Februarini. (2012). Pengaruh Sponsorship terhadap Brand Awareness Djarum Super Mild: Studi pada Event Jakarta International Java Jazz Festival 2012.168.

Cianfrone, B. A. (2018). Rising Above the Clutter: Brand Awareness of Sponsorships. Sport \& Entertainment Review, 4(1). 
Dharmawan Salim, A. (2013). IMC: Promosi, Iklan dan Sponsor Rokok Strategi Perusahaan Menggiring Remaja untuk Merokok. BENEFIT Jurnal Manajemen Dan Bisnis, 17(1), 58-65.

Karo Karo, P. (2019). Analysis of the Effects of Relational Marketing Towards Tourist Satisfaction Level On Organizing a Tourism Event In South Sumatra Province. Atlantis-Press.Com. https://orcid.org/0000-0002-2462-5297

Keller, K. L. (2013). BOOK : Strategic Brand Management 4Th. In Pearson Education Limited (Vol. 58).

Khuong, M. N., \& Kim Chau, N. T. (2017). The Effect of Event Sponsorship on Customer's Brand Awarness and Purchase Intention-A Case Study of Toyota Vietnam. Review of European Studies, 9(1). https://doi.org/10.5539/res.v9n1p148

Larasari, E., Lutfi, \& Mumtazah, L. (2018). Pengaruh Brand Ambassador Dan Event Sponsorship Terhadap Purchase Intention Dengan Brand Image Sebagai Variabel Intervening. Sains: Jurnal Manajemen Dan Bisnis, 11(1).

Masterman, G. (2012). Sponsorship: For a return on investment. In Sponsorship: For a Return on Investment. https://doi.org/10.4324/9780080942735

Mpolokeng Sephapo, C. (2017). Sponsorship investments: Do they deliver brand awareness for all sponsors? Management and Marketing, 12(1). https://doi.org/10.1515/mmcks-20170007

O’Halloran, R. M. (2014). Event Sponsorship. Tourism Management, 43, 68-69. https://doi.org/10.1016/j.tourman.2014.01.020

Pratiwi, A. (2017). Pengaruh Brand Awareness, Brand Association Dan Brand Loyalty Terhadap Purchase Intention Rokok Merek Surya Pro Mild Di Kota Kediri Afiyah. Journal of Chemical Information and Modeling, 53(9).

Speed, R., \& Thompson, P. (2000). Determinants of sports sponsorship response. Journal of the Academy of Marketing Science, 28(2). https://doi.org/10.1177/0092070300282004

Vitadiani, R., \& Mudiantono, D. H. (2016). Analisis Pengaruh Sponsorship, Pengalaman Konsumen, dan Promosi Penjualan Terhadap Minat Beli Konsumen dengan Kesadaran Merek Sebagai Variabel Intervening. Jurnal Manajemen, 5(4). 